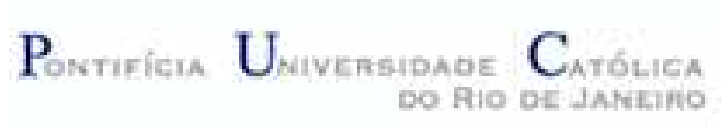

Cícero Antônio Cavalcante Barroso

\title{
UMA ANÁLISE INTERNALISTA DOS NOMES PRÓPRIOS
}

Tese apresentada ao Programa de Pós-Graduação em Filosofia do departamento de Filosofia da PUCRio como parte dos requisitos parciais para a obtenção do título de Doutor em Filosofia.

Orientador: Oswaldo Chateaubriand Filho 


\title{
"UMA ANÁLISE INTERNALISTA DOS NOMES PRÓPRIOS"
}

Tese apresentada como requisito parciais para a obtenção do grau de Doutor pelo Programa de Pós-Graduação em Filosofia do Departamento de Filosofia do Centro de Teologia e Ciências Humanas da PUC-Rio. Aprovada pela Comissão Examinadora abaixo assinada.

\author{
Oswaldo Chateaubriand Filho \\ Orientador \\ Departamento de Filosofia - PUC-Rio
}

Luis Carlos Pinheiro Dias Pereira

Departamento de Filosofia - PUC-Rio

Guido Imaguire

Universidade Federal do Rio de Janeiro - UFRJ

Ludovic Soutif

Universidade de São Paulo - USP

Marco Antônio Caron Ruffino

Universidade Federal do Rio de Janeiro - UFRJ

Prof. Paulo Fernando Carneiro de Andrade

Coordenador Setorial do Centro de Teologia

e Ciências Humanas - PUC-Rio

Rio de Janeiro, 15 de Março de 2010 
Todos os direitos reservados. É proibida a reprodução total ou parcial do trabalho sem autorização da Universidade, do autor e do orientador

\section{Cícero Antônio Cavalcante Barroso}

Graduou-se em Filosofia na UECE (Universidade Estadual do Ceará) em 1999. Obteve o título de Mestre em Filosofia na UFC (Universidade Federal do Ceará) em 2002. É professor efetivo do curso de Filosofia da Universidade Federal do Ceará no Cariri desde 2006, onde atua na área de Lógica, Filosofia da Linguagem e Filosofia da Mente.

Ficha Catalográfica

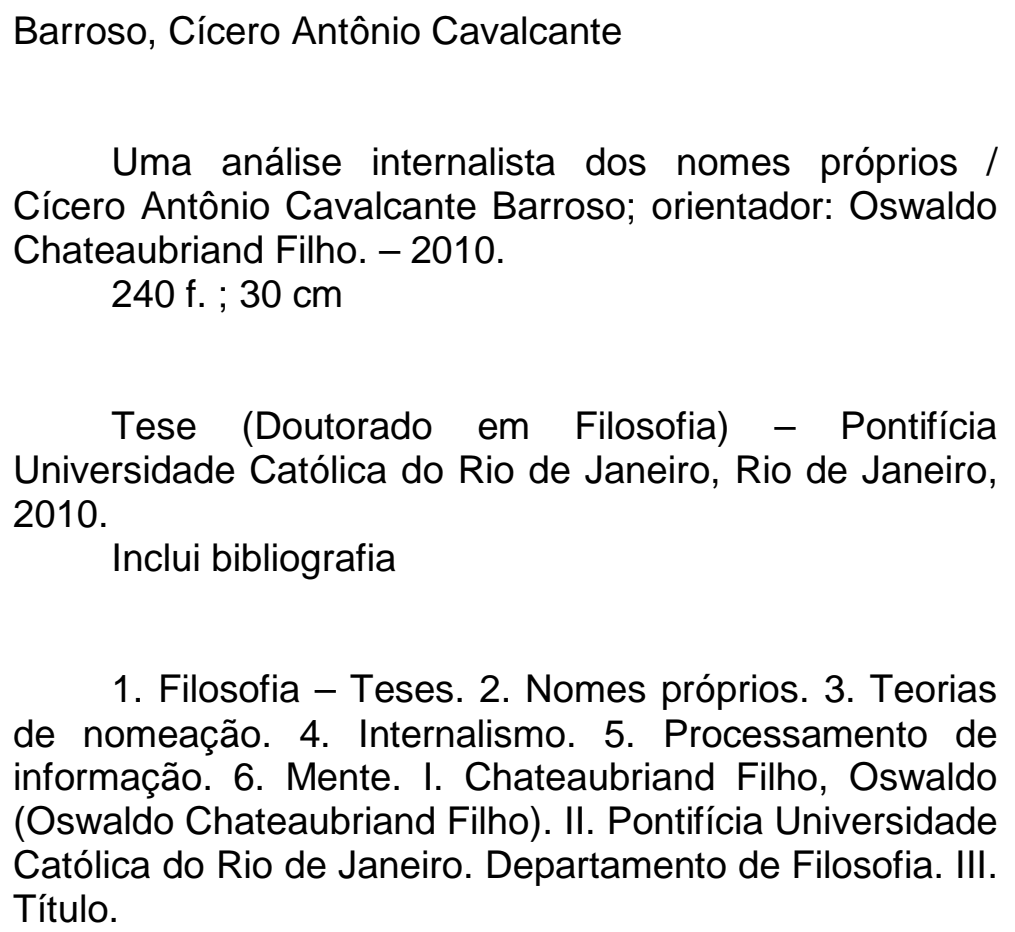

Tese (Doutorado em Filosofia) - Pontifícia Universidade Católica do Rio de Janeiro, Rio de Janeiro, 2010.

Inclui bibliografia

1. Filosofia - Teses. 2. Nomes próprios. 3. Teorias de nomeação. 4. Internalismo. 5. Processamento de informação. 6. Mente. I. Chateaubriand Filho, Oswaldo (Oswaldo Chateaubriand Filho). II. Pontifícia Universidade Católica do Rio de Janeiro. Departamento de Filosofia. III. Título. 


\section{Agradecimentos}

Ao professor Oswaldo Chateaubriand, pela sua atenção na leitura dos rascunhos que se transformaram neste trabalho. Por sua crítica cuidadosa, sua gentileza e generosidade intelectual. E por sua ajuda com assuntos burocráticos também.

À PUC-Rio por todos os auxílios que me foram concedidos.

Aos professores Danilo Marcondes, Ludovic Soutif, Luis Carlos Pereira e Marco Ruffino, que me ajudaram com suas críticas e observações.

A todos os que contribuíram para que eu pudesse conciliar o doutorado com minhas atividades na UFC: à professora Déborah Danowski (PUC-Rio), aos professores Kléber Amora, Átila Brilhante e Evanildo Coterski (UFC), a meus colegas da UFC-Cariri e aos funcionários da UFC que se envolveram no processo.

Ao meu amigo Tarcísio Pequeno, pelas discussões que tivemos sobre nomes próprios, de onde surgiram os germes das ideias que exponho neste trabalho.

Aos meus amigos Guido Imaguire, André Nascimento, Tárik Prata, Thiago Melo, Valdetônio Alencar e a todos os que fizeram parte do saudoso grupo de Filosofia Analítica de Fortaleza e discutiram comigo as partes iniciais deste trabalho. Ao primeiro agradeço também pelas considerações que me apresentou no dia da minha defesa e depois, por e-mail, e por me incluir no projeto do PROCAD que financiou meu primeiro semestre de doutorado e minhas viagens ao Rio.

À minha amiga Joelma Marques, por me dar ótimas dicas sobre Searle.

Aos meus alunos Aldenira Máximo, Elizângela Bezerra, Eugênia Silvestre, Jairo Ferreira e Marcel Marinho, para os quais apresentei os três primeiros capítulos desta tese. Suas dúvidas e observações instigantes me foram de grande ajuda.

A Maria Andreia Ferreira, por me ajudar com as palavras mágicas, com o Word 2007 e com o seu sorriso. 


\section{Resumo}

Barroso, Cícero Antônio Cavalcante; Chateaubriand Filho, Oswaldo (orientador). Uma Análise Internalista dos Nomes Próprios. Rio de Janeiro, 2010. 240p. Tese de Doutorado - Departamento de Filosofia, Pontifícia Universidade Católica do Rio de Janeiro.

Este trabalho tem o objetivo de mostrar que a função básica dos nomes próprios é a função de código e não a função referencial. Embora a função referencial seja uma das funções mais importantes dos nomes próprios, ela é dependente da função de código, ou seja, um nome próprio só pode ser um designador porque em primeiro lugar é um código. Como um código se distingue pelo fato de fornecer informação para um sistema de decodificação, nomes próprios também devem ser considerados informativos. Eles fornecem informação para nossos sistemas mentais de processamento de linguagem. Vê-se assim que a função de código dos nomes próprios só pode ser explicada dentro de uma perspectiva internalista, ou seja, dentro de uma perspectiva que leve em conta os fatores mentais envolvidos no uso de nomes próprios. A análise de nomes próprios feita neste trabalho esclarece quais são esses fatores e é isso que a torna internalista. Tal análise também dá suporte a um certo tipo de descritivismo, segundo o qual o conteúdo descritivo de um nome próprio é o conjunto de informações associadas ao nome quando ele é usado em dada ocasião.

\section{Palavras-chave:}

Nomes próprios, externalismo, internalismo, mente, informação, processamento, conteúdo descritivo. 


\section{Abstract}

Barroso, Cícero Antônio Cavalcante; Chateaubriand Filho, Oswaldo (advisor). An Internalist Analisys of Proper Names. Rio de Janeiro, 2010. 240p. Thesis - Departamento de Filosofia, Pontifícia Universidade Católica do Rio de Janeiro.

The purpose of this monograph is to show that the basic function of proper names is a coding function and not a referential function. Although the referential function is one of the most important functions of proper names, it is dependent on the coding function, i.e., a proper name can only be a designator because it is a code in the first place. Since a code is distinguished by the fact that it provides information to a decodification system, proper names must be considered informative too. They provide information to our language processing mental systems. So it is possible to see that the coding function of proper names can only be explained from an internalist perspective, that is to say, from a perspective that takes into account the mental factors involved in the use of proper names. The analysis of proper names in this work makes clear what these factors are, and it is this that makes it an internalist analysis. This analysis also supports a certain kind of descriptivism, according to which the descriptive content of a proper name is the information set associated to the name when it is used on a given occasion.

\section{Keywords:}

Proper names, externalism, internalism, mind, information, processing, descriptive content. 


\section{Sumário}

$\begin{array}{ll}\text { INTRODUÇÃO } & 011\end{array}$

$1^{\text {a }}$ PARTE

A DISCUSSÃO CLÁSSICA SOBRE NOMES PRÓPRIOS 018

Capítulo 1

NOÇÕES CENTRAIS NA DISCUSSÃO CLÁSSICA SOBRE NOMES

$\begin{array}{ll}\text { PRÓPRIOS } & 019\end{array}$

1.1. Referência e denotação 020

1.2. Sentido, significado e outras noções afins 032

Capítulo 2

AS TEORIAS DE NOMEAÇÃO 049

2.1. Considerações preliminares 049

2.2. Descritivismo 052

2.3. Causalismo 064

2.4. Observações 076

Capítulo 3

PROBLEMAS NAS TEORIAS DE NOMEAÇÃO E O DESAFIO DOS NOMES

$\begin{array}{ll}\text { VÁCUOS } & 079\end{array}$

3.1. Problemas com o causalismo 080

3.2. Limitações do descritivismo 097

3.3. O desafio dos nomes próprios vácuos 099

$2^{\mathrm{a}}$ PARTE

MENTE E LINGUAGEM: AS BASES DO INTERNALISMO

$\begin{array}{ll}\text { LINGUÍSTICO } & 108\end{array}$

Capítulo 4

A CONCEPÇÃO COMPUTACIONAL DE MENTE 109 
4.1. A mente como uma substância 110

4.2. A mente como um programa de computador 115

$\begin{array}{ll}\text { 4.3. As objeções de Searle } & 127\end{array}$

Capítulo 5

$\begin{array}{ll}\text { O INTERNALISMO DE CHOMSKY } & 137\end{array}$

$3^{\text {a }}$ PARTE

UMA ANÁLISE INTERNALISTA DOS NOMES PRÓPRIOS 165

Capítulo 6

A FUNÇÃO OPERACIONAL: A FUNÇÃO BÁSICA DOS NOMES

$\begin{array}{ll}\text { PRÓPRIOS } & 166\end{array}$

6.1. Considerações preliminares 166

6.2. A noção de informação 167

6.3. A função operacional da linguagem e dos nomes próprios 176

6.4. ProgX: um modelo para o processamento mental de nomes próprios 190

Capítulo 7

DUAS QUESTÕES SOBRE NOMES PRÓPRIOS 204

7.1. A origem das questões 204

7.2. A primeira questão: Nomes próprios têm um conteúdo descritivo? 208

7.3. A segunda questão: O que acontece quando um nome próprio é usado $\begin{array}{ll}\text { referencialmente? } & 218\end{array}$

CONCLUSÃO 232

REFERÊNCIAS BIBLIOGRÁFICAS 237 
"What's in a name?"

(Romeo and Juliet, Act II, Scene II) 